\title{
Pathotyping of recent Indian field isolates of Marek's disease virus serotype 1
}

\author{
P. SURESH ${ }^{1}$, J. JOHNSON RAJESWAR ${ }^{2}$, K. SUKUMAR ${ }^{3}$, T. J. HARIKRISHNAN ${ }^{4}$, P. SRINIVASAN ${ }^{5}$
}

\begin{abstract}
${ }^{1}$ Department of Veterinary Microbiology, Veterinary College and Research Institute, Namakkal - 637 002, India; ${ }^{2}$ Department of Veterinary Microbiology, Veterinary College and Research Institute, Tirunelveli - 627 001, India; ${ }^{3}$ Department of Veterinary Public Health and Epidemiology, Veterinary College and Research Institute, Tirunelveli - 627 001, India; ${ }^{4}$ Registrar, Tamilnadu Veterinary and Animal Sciences University, Chennai - 600051, India; ${ }^{5}$ Poultry Disease Diagnosis and Surveillance Laboratory, Namakkal - 637002, India
\end{abstract}

Received July 1, 2014; accepted May 15, 2015

\begin{abstract}
Summary. - A study was undertaken to assess the virulence of Marek's disease virus (MDV) serotype 1 field isolates obtained from poultry flocks of southern part of India. Five representative MDV serotype 1 strains were isolated from eighty-six blood samples collected from fifteen farms. Three out of five isolates which were free from avian leukosis virus (ALV) and reticuloendotheliosis virus (REV) were adapted in chicken embryo fibroblast (CEF) culture and designated as Ind/TN/11/01, Ind/KA/12/02 and Ind/TN/12/03. Pathotyping assay was conducted in two trials. In the first trial, non-vaccinated chickens were challenged (trial I), while in second trial, two types of vaccinated chickens along with non-vaccinated controls were challenged (trial II). Birds inoculated with field isolate Ind/TN/12/03 had very low body ( $75.34 \pm 3.04 \mathrm{~g} 15$ days post infection (dpi)) and bursa Fabricii weight $(1.64 \pm 0.06$ at $15 \mathrm{dpi})$ when compared to those inoculated with the other two isolates (Ind/TN/11/01 and Ind/KA/12/02) and uninoculated controls (body weight $111.33 \pm 1.30 \mathrm{~g}$ and bursa Fabricii weight $4.33 \pm 0.1115 \mathrm{dpi}$ ). Incidence of early mortality syndrome (53\%) and lymphoma (86\%) induced by Ind/ $\mathrm{TN} / 12 / 03$ was comparable with very virulent strains published elsewhere. In protection test, the percentage of Marek's disease (MD) incidence induced by Ind/TN/12/03 was $57.5 \%$ and $25 \%$ in monovalent and bivalent vaccine inoculated birds respectively compared to uninoculated control $(100 \%)$. Based on the above findings in pathotyping experimental trials with a supportive evidence of histopathological observations, isolate Ind/ $\mathrm{TN} / 12 / 03$ was considered as very virulent MDV and other two isolates were considered as virulent MDVs.
\end{abstract}

Keywords: pathotypes of Marek's disease virus; incidence of lymphoma, early mortality syndrome; HVT and SB1

\section{Introduction}

Marek's disease (MD) is one of the most common lymphoproliferative diseases of chickens which result in mononuclear cell infiltration of one or more of the visceral organs and nerves (Witter and Schat, 2003). Marek's disease has

E-mail: vet_suresh@yahoo.com, p.suresh@tanuvas.org.in; phone: +9198433-33208.

Abbreviations: $\mathrm{ALV}=$ avian leukosis virus; $\mathrm{CEF}=$ chicken embryo fibroblast; DEF = duck embryo fibroblast; EMS = early mortality syndrome; $\mathrm{dpi}=$ days post infection; $\mathrm{dpc}=$ days post challenge; $\mathrm{MD}=$ Marek's disease; MDV(s) = Marek's disease virus(es); $\mathrm{REV}=$ reticuloendotheliosis virus; $\mathrm{vv}=$ very virulent a tremendous economic impact, firstly because of continuing losses due to the disease and secondly because of cost of vaccination (Suresh et al., 2013). This avian herpes virus is commonly termed as Marek's disease virus and it belongs to the family Herpersviridae, the subfamily Alphaherpesvirinae, and the genus Mardivirus (Marek's disease like viruses). Marek's disease virus has been divided into three serotypes based on their biological properties, by using the type specific monoclonal antibodies (Bullow and Biggs, 1975) as serotype 1, 2 and 3. Serotype 1 includes oncogenic MDV, serotype 2 includes non-oncogenic MDV (SB1) and serotype 3 includes herpesvirus of turkey (HVT) (Witter and Schat, 2003). Serotype $1 \mathrm{MDV}$ strains are further classified into four pathotypes based on induction of lymphoproliferative 
lesions in vaccinated chickens as mild (m) MDV, virulent (v) MDV, very virulent (vv) MDV, very virulent plus (vv+) MDV (Witter et al., 2005). Soon after the isolation of MDV serotype 1 (MDV-1), the first vaccine became available based on either highly passaged attenuated MDV-1 (Churchill et al., 1969) or the serologically related herpesvirus of turkey (HVT) serotype 3 of MDV like viruses (Okazaki et al., 1970). The major potential disadvantage inherent in $\mathrm{MD}$ vaccines is their inability to prevent the infection and shedding of the virus, although vaccines can effectively reduce tumor formation by the virus in MDV infected birds. Due to the inability of vaccines to confer sterile immunity, MDV has increased its virulence against the selection pressure imposed by vaccination (Schat and Baranowski, 2007) and that has been evidenced by the emergence of virulent pathotypes in vaccinated flocks. Vaccine failure can be due to challenge from highly virulent MDV pathotypes, especially in areas of chicken density (Bublot and Sharma, 2004). Determination of the pathotypes for MDV has a number of useful applications; the most frequent application is to investigate the cause of excessive MD losses in vaccinated flocks. Another application is the detection of new pathotypes and to document further evolution of MD viral strains having greater virulence. Evaluation of number of MDV isolates for the pathotyping gives a clear picture of the isolatable virus population for each pathotype intern to find a suitable vaccine candidate. It also needs to be studied, to improve the pathotype assay to fit local laboratory conditions.

\section{Materials and Methods}

Experimental birds. Day-old layer birds were obtained from Lohmann Franchise in India and housed in isolators immediately after hatch. All animal procedures were performed in accordance with CPCSEA regulations, with the approval of the institutional animal ethical committee.

Isolation of serotype $1 \mathrm{MDV}$. Eighty-six blood samples were collected from 15 commercial layer and broiler breeder farms throughout Tamilnadu and parts of Karnataka states of India in which Marek's disease outbreak occurred in spite of vaccination with monovalent and bivalent vaccines. EDTA blood samples from individual farms were pooled. Primary cell cultures were prepared from the 10/12-day-old embryonated duck/chicken eggs according to the protocol of supplemental assay methods (2005), Centre for Veterinary Biologicals, USDA. Lymphocytes that were positive for 132 bp repeats in PCR were collected aseptically from the blood samples by using ficoll-plaque assay and co-cultivated with duck embryo fibroblasts (DEF) as described by Tian et al. (2012). The co-cultivated monolayers were observed every day for five to seven days. After three blind passages, the presence of MDV serotype 1 in DEF was verified by PCR by detection of 132 bp repeat sequence. The DEF harvests which were positive for $132 \mathrm{bp}$ repeats having no contamination of avian leukosis virus (ALV) and reticuloendotheliosis virus (REV) screened by multiplex PCR kit (Gopal et $a l ., 2012$ ) were used for further passages in CEF monolayer until the appearance of typical plaque formation. The infected monolayers were observed every day for the formation of plaques up to 7 days. Once the plaques appeared, $1 / 10^{\text {th }}$ portion of the cell monolayer was scrapped using small pipette and transferred to fresh culture. Even if the plaques were not observed after seventh day of incubation, $1 / 10^{\text {th }}$ portion of the cell monolayer was collected and transferred to another monolayer for the next passage. Since, it is cell associated virus we didn't use freeze-thaw disruption. Fresh culture was prepared for every challenge (Handberg et al., 2001). The inoculum was titrated by counting the plaque forming units (PFU).

Pathotyping trial. Pathotyping of the field isolates was carried out considering the basic facts of "best fit" pathotyping assay (Witter et al., 2005; Dudnikova et al., 2007) which involved three groups of chickens; non-vaccinated, FC126-vaccinated (HVT) and bivalentvaccinated $(\mathrm{SB} 1+\mathrm{HVT})$ with slight modification to suit local condition. For convenience, the assay was conducted in two trails. First, non-vaccinated chickens were challenged (trial I). In second trial, two types of vaccinated chickens along with non-vaccinated control were challenged (trial II). The field isolate identified as very virulent in the first trial (trial I) alone was used in protection test (trial II). To assess the pathotypes of field isolates 150 of one-day-old unvaccinated layer chicks were randomly divided into two major groups. The group (A) was designed to analyse decrease in body weight and relative bursa Fabricii weight. Ninety birds were divided into three groups with 25 birds inoculated by three field isolates and 15 birds with negative control. The birds were inoculated with $1,000 \mathrm{PFU}$ of challenge virus of respective isolate via intra-abdominal route $(200 \mu \mathrm{l} / \mathrm{bird})$ except negative controls which received $200 \mu \mathrm{l} /$ bird of sterile saline buffer at day 1 . The bursa and body weight were measured 10 and 15 dpi. Relative bursal weight was the bursal weight divided by the body weight $x 1,000$. The group (B) was designed to compare the lymphoma incidence among the isolates. The remaining 60 birds were divided into four groups comprising 15 birds each inoculated by three field isolates along with one negative control. The birds were intravenously inoculated with $1,000 \mathrm{PFU}$ of challenge virus with respective isolates $(200 \mu \mathrm{l} / \mathrm{bird})$ and negative controls received $200 \mu \mathrm{l} /$ bird of saline buffer at day 6 . The incidence of lymphoma was assessed after 16 weeks, with daily examination for clinical signs. All the dead birds were observed for gross MD lesions. At the termination of the experiment, all remaining birds were sacrificed and necropsied. Presence of early mortality syndrome (EMS) based on mortality between 8 and 18 days post inoculation without MD lesions and gross MD lesions in visceral organs were recorded. The spleen, liver, heart and kidney were examined microscopically. To assess the protective efficacy of monovalent and bivalent vaccines, the isolate behaving like very virulent in the first trial was used for the trail II. Hundred and 1-dayold layer chickens were separated into three groups. Two groups of 40 chickens were vaccinated with one dose of HVT and HVT plus SB1, which were obtained from the commercial vaccine market. 
Remaining 20 birds were maintained as unvaccinated control. The vaccine strain CVI988 (Rispens) was not used as it is not available in India. Six days later, all the birds from each group, including an unvaccinated control, were challenged with approximately 1,000 $\mathrm{PFU} /$ bird of Ind/TN/12/03 (local very virulent isolate). Chickens were observed for 16 weeks after challenge. About five new growing feather tips from each chicken were collected 20 and 30 days post challenge (dpc), and after DNA extraction PCR for MDV serotype 1 was done. The bursa and body weight measurement was done after 6 weeks. The body weight and spleen weight was measured on $12^{\text {th }}$ and $16^{\text {th }}$ week. Birds that died during experimental period or that were killed at the end of the experiment were examined for gross lesions. Suspected lesions were microscopically confirmed. Pathotypes were identified by the comparison with appropriate reference strains described by earlier workers. Pathotype of each field virus was identified by comparing its pathogenicity with reference strain that it most closely resembled, especially in the most critical parameters. This was usually done by visual inspection of the data (i.e. the "best fit" method).

Histopathological examination. The formalin fixed tissues were processed by paraffin embedding. The sections were cut into thickness of 5-6 microns with automatic microtome (Rotary Microtome RM 2125, Leica, China) and were stained with haematoxyline and eosin (H \& E) staining (Bancroft and Stevens, 1996). The H \& E stained slides were analysed under microscope and histopathological changes were recorded.

Statistical analysis. The trial data were analysed by CRD using SPSS version 17, the difference between means compared by using Tukey test.

\section{Results}

\section{Virus recovery}

Five representative MDV serotype 1 strains were isolated from 5 of 15 farms by culturing in DEFs (33.33\%). Three out of five MDV isolates were free of ALV and REV. They adapted to CEFs very well and could cause typical cytopathic effect (CPE) (MDV serotype 1 plaques) after 2-4 passages (Fig. 1). The MDV isolates of two farms were discarded because of the contamination of ALV or REV. The isolates were designated as Ind/TN/11/01, Ind/KA/12/02 and Ind/ $\mathrm{TN} / 12 / 03$.

\section{Pathotyping trial I}

One-day-old layer chicks were inoculated with three isolates and observed for body and bursa Fabricii weights to compare the pathogenicity. There was a severe reduction not only in body weight but also in relative bursal weight 10 and $15 \mathrm{dpi}$ (Table 1). The reduction in body and relative bursal weight induced by
Ind/TN/12/03 was more severe than those induced by Ind/ TN/11/01 and Ind/KA/12/02 strains. The body and bursal weight in all the three isolates was lower when compared with uninoculated controls but changes in Ind/TN/12/03 isolate infection were found to be more prominent.

Table 2 summarizes the incidence of early mortality syndrome (EMS) and MD lymphoma in chickens inoculated with all the three isolates. The body weights 30 and $50 \mathrm{dpi}$ and overall mortality were also recorded (Table 2 ). Chickens infected by all the three isolates had decreased body weight when compared to uninoculated controls but changes in Ind/ $\mathrm{TN} / 12 / 03$ isolate infection were found to be more prominent. The incidence of lymphoma, EMS and overall mortality was much higher in the isolate Ind/TN/12/03 inoculated group. Fig. 2 shows various gross pathological changes induced in experimental birds by field isolates.

\section{Pathotyping trial II}

The protective capacities of monovalent (HVT) and bivalent (HVT and SB1) MD vaccines were studied against challenge with highly aggressive Ind/TN/12/03. The presence of challenge virus in experimental birds was analysed by PCR with DNA extracted from feather tips from vaccinated and uninoculated chickens 20 and $30 \mathrm{dpi}$ (Fig. 3). None of the chickens vaccinated with HVT alone or combined with SB1 were completely protected against challenge with Ind/ $\mathrm{TN} / 12 / 03$. The protective levels of MD vaccines were usually lower against challenge with Ind/TN/12/03. Changes observed in body weights and relative bursal weight along with spleen weights at $6^{\text {th }}$ week are summarized in Table 3 and changes observed in body and spleen weights at $12^{\text {th }}$ and $16^{\text {th }}$ week are summarized in Table 4 . Table 5 summarizes the percentage mortality, lymphoma incidence and MD percentage in experimental birds up to $16^{\text {th }}$ week. Various gross pathological conditions induced in experimental birds by isolate Ind/TN/12/03 at $6^{\text {th }}, 12^{\text {th }}$ and $16^{\text {th }}$ week respectively in protection test are shown in Fig. 4.

\section{Histopathology}

Multiple islands of lymphocytic aggregation among hepatic parenchyma and in spleen marked infiltration of pleomorphic neoplastic lymphocytes was observed in Ind/ TN/12/03 inoculated birds. Distorted myocardium due to heavy infiltration of pleomorphic lymphoid cells and marked thickening of mucosa and grossly thickened proventriculus due to massive infiltration of mononuclear cells was observed in Ind/TN/12/03 inoculated birds (Fig. 5).

Based on the above findings (trial I \& II) isolate Ind/ TN/12/03 was designated as very virulent MDV. The other two isolates (Ind/TN/11/01 and Ind/KA/12/02), based on results from trial I, were considered as virulent MDVs. 


\section{Discussion}

The term "pathotype", although properly used to designate classes of organisms that induce different types of pathology, where in the case of Marek's disease, applied to designate differences in the virulence of isolates measured (primarily) by the level of disease induced. The viruses isolated in this study designated as Ind/TN/11/01, Ind/KA/12/02 had many features of virulent pathotypes and isolate Ind/TN/12/03 behaved like very virulent MDVs isolated in the US, Europe and Asia.

One of the distinguishing features of hypervirulent MDV strains, such as the Ind/TN/12/03 strain, is the ability to induce rapid-onset of cytolytic disease characterized by marked atrophy of the lymphoid organs and high mortality. These findings are in accordance with Barrow and Venugopal (1999). Some laboratories applied term "very virulent" (vv), if the isolate caused significant disease in vaccinated chickens (Powell and Lombardini, 1986; Jurajda and Halouzka, 1988). In some cases, an isolate was termed vv pathotype only because it was derived from vaccinated flocks with excessive MD losses (Witter, 1988). These reports are in accordance with present study as all the recovered isolates were obtained from vaccinated flocks.

Imai and coworkers (Imai and Yuasa, 1988; Imai et al., 1992) designated isolates as vv by multiple criteria, including a comparison with prototype vv strains Md5 and RB1B. Liu et al. (1996) typed isolates as vv by comparison with the control strain GA. The C12/130 strain was identified as having special virulence properties by comparison with the prototype strain HPRS-16 (Venugopal et al., 1996), although a pathotype designation was not applied in this work. These procedures were not used in this study as the prototype viruses are not available in India.

Witter et al. (1980) reported that some vv isolates induced EMS. However, RB-1B did not cause EMS (Schat et al., 1982). In the present study, all the isolates viz. Ind/TN/11/01 (33\%), Ind/KA/12/02 (40\%) and Ind/TN/12/03 (53\%) induced EMS. Witter (1983) reported that vv MDV caused an EMS characterized by death without tumors within a few weeks of inoculation. The data showed that some vv MDVs induced high rates of early mortality in some chicken strains, although the extent varied according to chicken strains used. However, none of the chickens inoculated with KOMD-IC died before $57 \mathrm{dpi}$ (Sung, 2002). The possible explanations for this discrepancy may be the difference of virus dose, age of inoculation, or chicken strain used. In the experiment conducted by Sung (2002), 6-day-old chicks were inoculated with $100 \mathrm{PFU}$, where the dose was about five times lower than in the study by Witter (1983). In our experiment, all the isolates showed EMS with varying degree; however this may be due to 10-times higher virus intravenous inoculation of 6-day-old chicks.
Incidence of lymphoma was very high $(86 \%)$ in Ind/ TN/12/03 inoculated group compared to Ind/KA/12/02 (66\%) and Ind/TN/11/01 (50\%). There was 93 and 62\% incidence of lymphoma induced by a very virulent strain KOMD-IC and virulent strain JM respectively reported by Sung (2002). In our study only the strain Ind/TN/12/03 produced up to $86 \%$ of lymphoma which is more or less equivalent to KOMD-IC. Remaining two isolates behaved like virulent strain JM. Imai et al. (1992) experienced 100\% of lymphoma incidence when they studied very virulent strains like Md5, MS2 and virulent strain JM; however this may be due to the fact that they used MD susceptible P2 chickens. Based on these comparisons the isolates Ind/ $\mathrm{KA} / 12 / 02$ and Ind/TN/11/01 were designated as virulent pathotypes.

Massive infiltration of pleomorphic neoplastic lymphocytes was noticed in the spleen and myocardium resulting in damaged heart. Marked thickening of proventriculus mucosa due to heavy infiltration of mononuclear cells causes the grossly thickened organs in Ind/TN/12/03 inoculated birds. These findings were in accordance with Kamaldeep et al. (2007).

The major factor in pathotypic classification is the association of pathotype with the field disease. Each new pathotype appears to be associated with a new wave of MD losses in commercial chicken flocks. Also, each pathotype appears to be associated with the ability to be protected by specific $\mathrm{MD}$ vaccines. For example, pathotype strains induced severe disease in nonvaccinated chickens, but less severe disease in chickens vaccinated with HVT. In contrast, vv pathotype strains induced severe disease in HVT-vaccinated chickens, but less severe disease in chickens vaccinated with bivalent vaccines composed of HVT and selected serotype 2 strains such as SB-1 or $301 \mathrm{~B} / 1$. Hence it becomes inevitable to assess the protective efficacy of existing vaccines against vv strain Ind/TN/12/03 isolated in this study.

Marek's disease is controlled primarily by the widespread use of a number of live attenuated vaccines since the 1970s. These include the antigenically related herpes virus of turkey (HVT), MDV-2 strain SB-1, as well as the widely used CVI988 (Rispens) (Witter, 2001). Nair, (2005) stated that even though vaccines have been generally very successful in reducing the losses from the disease, vaccination strategy has not been very effective in preventing the evolution of viruses towards greater virulence. This kind of situation also exists in India. This has necessitated the periodic introduction of different generations of vaccines to keep up with continuing increase in virulence of the MDV and it is justified by isolation of different pathotypes classified as virulent MDV and vv MDV in this study. Even though the molecular determinants associated with the increasing virulence of these pathotypes have been identified, the genome sequence of these viral pathotypes indicates changes in parts of their genomes. 
Fig. 1

Plaques induced by MDV serotype 1 field isolates in chicken embryo fibroblasts

Typical specific MDV serotype 1 plaques induced by isolate: (a) Ind/TN/11/01; (b) Ind/KA/12/02 in CEF at $3^{\text {rd }}$ passage level; (c) Ind/TN/12/03 in CEF at $2^{\text {nd }}$ passage; and (d) uninfected chicken embryo fibroblast culture. (a)

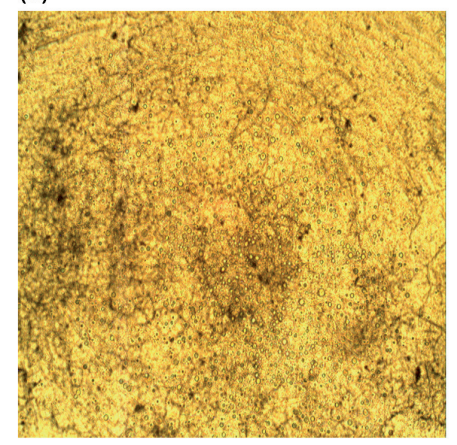

(c)

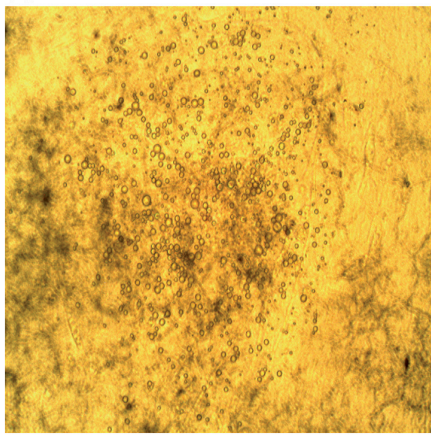

(b)

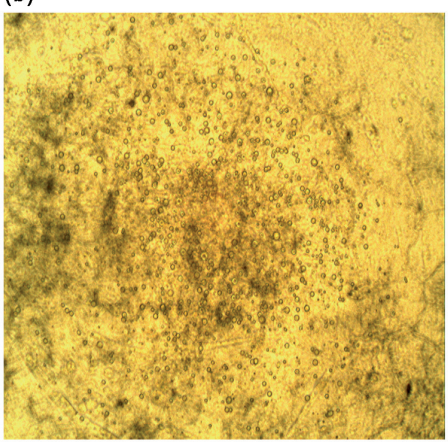

(d)

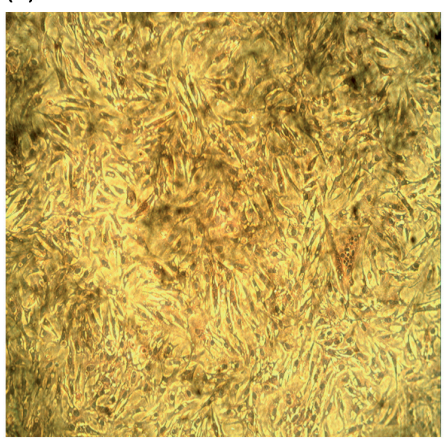

(a)

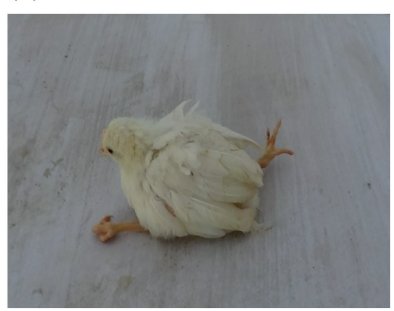

(d)

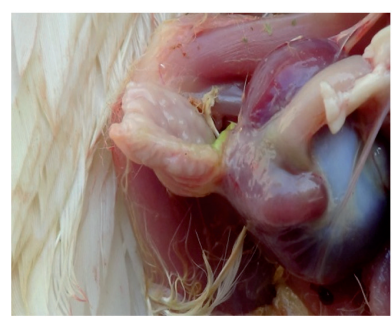

(g)

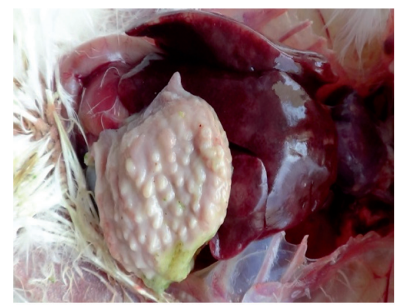

(b)

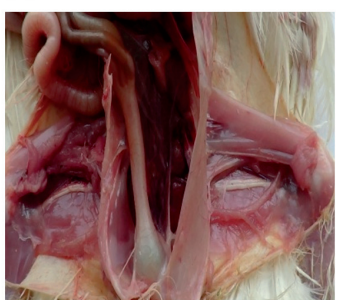

(e)

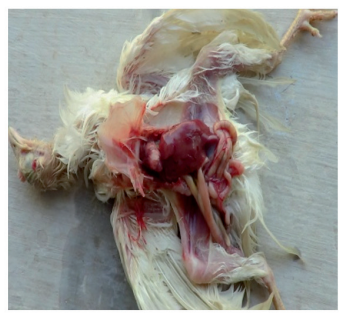

(h)

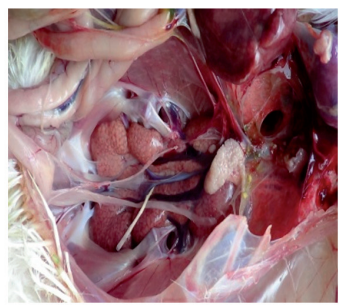

(c)

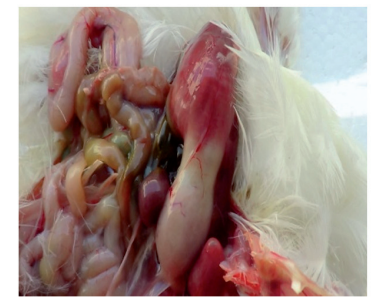

(f)

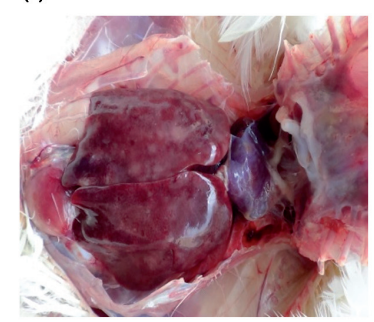

(i)

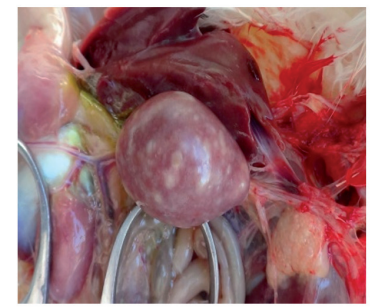
week after infection. 
(a)

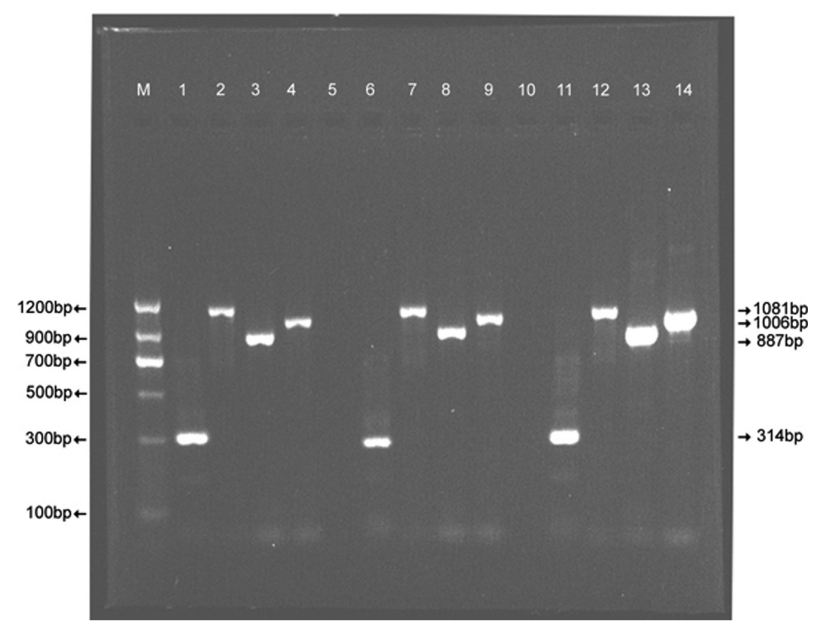

(b)

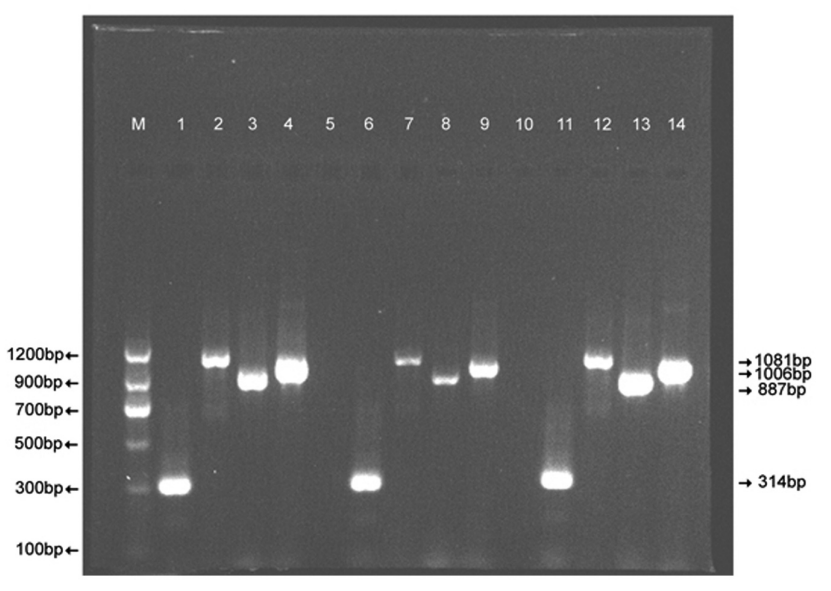

Fig. 3 Agarose gel showing the presence of challenge virus DNA in feather follicle by PCR

(a) Agarose gel electrophoresis pattern showing amplified PCR product of 132 bp repeats, meq, pp38 and vIL8 genes from the DNA extracted from feather follicle samples collected 20 dpi from vaccinated and Ind/TN/02/03 challenged birds. Lane (M) 1200 bp DNA marker; (1-4) monovalent vaccinated birds; (1, 6 \&11) 132 bp repeats; (6-9) bivalent vaccinated birds; (2, 7 \& 12) meq gene; (11-14) unvaccinated challenged birds; (3, 8 \& 13) vIL8 gene; (4, 9 \& 14) pp38 gene; (5 \& 10) negative control.

(b) Agarose gel electrophoresis pattern showing amplified PCR product of 132 bp repeats, meq, pp38 and vIL8 genes from the DNA extracted from feather follicle samples collected $30 \mathrm{dpi}$ from vaccinated and Ind/TN/02/03 challenged birds. Lane (M) 1200 bp DNA marker; (1-4) monovalent vaccinated birds; (1, 6 \&11) 132 bp repeats; (6-9) bivalent vaccinated birds; (2, 7 \& 12) meq gene; (11-14) unvaccinated challenged birds; (3, 8 \& 13) vIL8 gene; $(4,9 \& 14)$ pp38 gene.

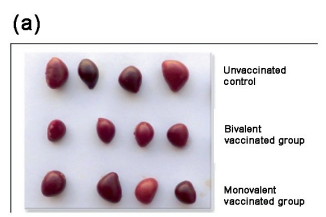

(d)

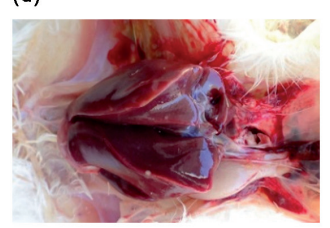

(g)

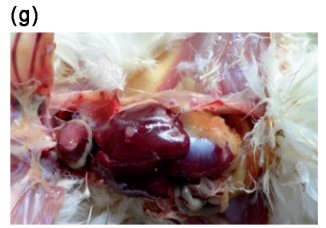

(j)

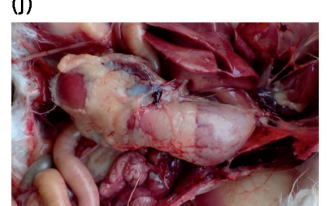

(m)

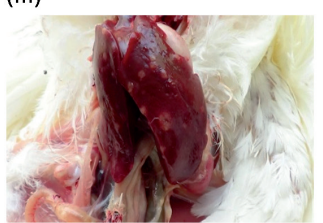

(b)

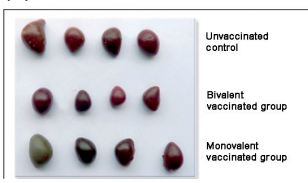

(e)

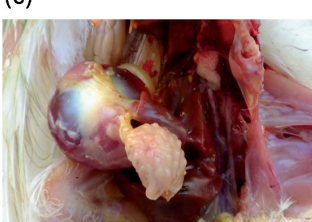

(h)

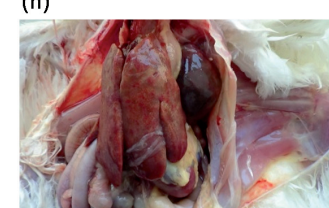

(k)

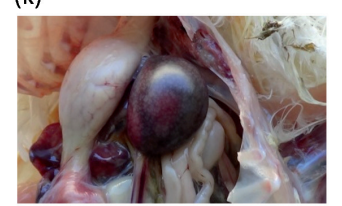

(n)

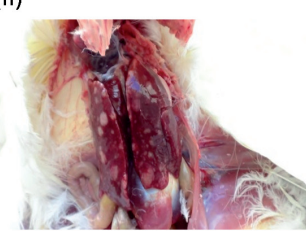

(c)

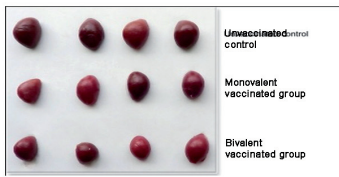

(f)

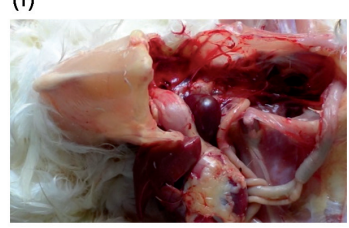

(i)

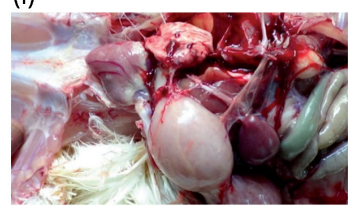

(I)

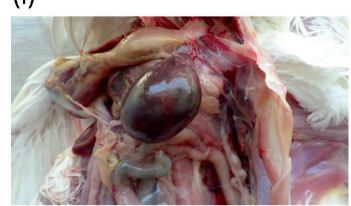

(o)

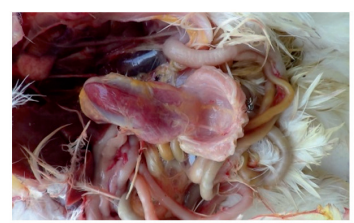

Fig. 4

Gross pathology induced by MDV field isolate (Ind/TN/12/03) in vaccinated birds (trial-II) Spleen with hypertrophic changes in (a) $6^{\text {th }}$ week, (b) $12^{\text {th }}$ week, (c) $16^{\text {th }}$ week; (d) liver showing focal lymphoma, (e) proventriculus thickening, (f) proventriculus thickening and enlargement of spleen in $6^{\text {th }}$ week (HVT); (g) liver showing focal lymphoma in $12^{\text {th }}$ week (HVT+SB1); (h) diffuse enlargement of liver, (j) thickening of proventriculus and multifocal lymphoma in heart in $12^{\text {th }}$ week (HVT); (i) proventriculus thickening, $(\mathrm{k})$ proventriculus thickening and enlarged spleen with multifocal necrosis in 12th week (HVT+SB1); (1) enlarged spleen in $12^{\text {th }}$ week (HVT); (m) enlarged liver with few lymphoma in $16^{\text {th }}$ week $(\mathrm{HVT}+\mathrm{SB} 1)$; (n) enlarged liver with multiple lymphoma, (o) proventriculus wall thickening in $16^{\text {th }}$ week (HVT). 
Table 1. Decrease in body and relative bursa Fabricii weight induced by field isolates 10 and 15 dpi

\begin{tabular}{|c|c|c|c|c|c|}
\hline No. & MD isolates ${ }^{\mathrm{A}}$ & $\begin{array}{c}\text { Body } \\
\text { weight }(\mathrm{g})(10 \mathrm{dpi})\end{array}$ & $\begin{array}{c}\text { B/B ratio } \\
(10 \text { dpi })\end{array}$ & $\begin{array}{l}\text { Body weight (g) } \\
\text { (15 dpi) }\end{array}$ & $\begin{array}{c}\text { B/B ratio }{ }^{\mathrm{B}} \\
\text { (15 dpi) }\end{array}$ \\
\hline 1. & Ind/TN/11/01 & $65.40 \pm 1.08^{\mathrm{b}}$ & $2.14 \pm 0.04^{\mathrm{b}}$ & $90.36 \pm 2.15^{\mathrm{b}}$ & $2.05 \pm 0.02^{\mathrm{b}}$ \\
\hline 2. & Ind/KA/12/02 & $63.38 \pm 0.93^{b}$ & $1.95 \pm 0.05^{\mathrm{b}}$ & $86.42 \pm 2.12^{\mathrm{b}}$ & $2.01 \pm 0.02^{\mathrm{b}}$ \\
\hline 3. & Ind/TN/12/03 & $53.70 \pm 1.01^{\mathrm{a}}$ & $1.78 \pm 0.05^{\mathrm{a}}$ & $75.34 \pm 3.04^{\mathrm{a}}$ & $1.64 \pm 0.06^{\mathrm{a}}$ \\
\hline 4. & Uninoculated & $73.23 \pm 0.73^{c}$ & $3.82 \pm 0.06^{\mathrm{c}}$ & $111.33 \pm 1.30^{c}$ & $4.33 \pm 0.11^{\mathrm{c}}$ \\
\hline
\end{tabular}

Values are expressed as mean \pm standard error from 10 and 15 chickens per group at 10 dpi and 15 dpi, respectively. In each column, different superscript letters are statistically significant at $P<0.01$. The values carrying different superscript letters $(\mathrm{a}, \mathrm{b})$ are significantly different, values carrying same superscript $(\mathrm{a}, \mathrm{a})$ are statistically not significant. ${ }^{\mathrm{A}} 1$-day-old chicks were intra-abdominally inoculated with a $1,000 \mathrm{PFU} / \mathrm{chick}$ of MDV. ${ }^{\mathrm{B}}$ Weight of bursa of Fabricii/body weight x 1,000.

Table 2. Comparison of MD lymphoma incidence in field isolates inoculated chickens

\begin{tabular}{|c|c|c|c|c|c|c|c|}
\hline \multirow{2}{*}{ No. } & \multirow{2}{*}{ MD isolate ${ }^{A}$} & \multirow{2}{*}{ No. of birds } & \multicolumn{2}{|c|}{ Body weight $(\mathrm{g})^{\mathrm{B}}$} & \multirow{2}{*}{$\operatorname{EMS}(\%)$} & \multirow{2}{*}{$\begin{array}{l}\text { MD lymphoma } \\
\text { incidence }(\%)^{\mathrm{C}}\end{array}$} & \multirow{2}{*}{ Overall mortality (\%) } \\
\hline & & & $30 \mathrm{dpc}$ & $50 \mathrm{dpc}$ & & & \\
\hline 1. & Ind/TN/11/01 & 15 & $202.46 \pm 2.56^{\mathrm{b}}$ & $398.07 \pm 5.32^{\mathrm{b}}$ & $5 / 15(33)$ & $5 / 1050)$ & $8 / 15(53)$ \\
\hline 2. & Ind/KA/12/02 & 15 & $195.65 \pm 3.52^{\mathrm{b}}$ & $387.75 \pm 6.28^{\mathrm{b}}$ & $6 / 15(40)$ & $6 / 9(66)$ & $10 / 15(66)$ \\
\hline 3. & Ind/TN/12/03 & 15 & $178.24 \pm 5.07^{\mathrm{a}}$ & $363.64 \pm 5.04^{\mathrm{a}}$ & $8 / 15(53)$ & $6 / 7(86)$ & $12 / 15(80)$ \\
\hline 4. & Uninoculated & 15 & $256.05 \pm 2.36^{\mathrm{c}}$ & $513.48 \pm 5.87^{c}$ & Nil & $0 / 15(0)$ & $1 / 15(6)$ \\
\hline
\end{tabular}

${ }^{\mathrm{A}} 6$-day-old chickens were intravenously inoculated with 1,000 PFU of MDV isolates/chick. ${ }^{\mathrm{B}} \mathrm{Mean} \pm$ standard error. In each column, different superscript letters are statistically significant at $P<0.01$. The values carrying different superscript letters $(\mathrm{a}, \mathrm{b})$ are significantly different, values carrying same superscript (a, a) are statistically not significant. ${ }^{C} \mathrm{MD}$ lymphoma examined in $16^{\text {th }}$ week post inoculation.

Table 3. Comparison of body weight, bursa of Fabrici weight ratio and spleen weight in vaccinated (bivalent and monovalent) and unvaccinated birds challenged with isolate Ind/TN/12/03 in $6^{\text {th }}$ week

\begin{tabular}{|c|c|c|c|c|c|}
\hline No. & Vaccinated group & No. of birds & Body weight $(g)^{A}$ & $\mathrm{~B} / \mathrm{B}_{\text {ratio }^{\mathrm{B}}}$ & Spleen weight $(g)^{c}$ \\
\hline 1. & Bivalent (SB1 + HVT) & 10 & $368.33 \pm 3.40^{c}$ & $0.46 \pm 0.02^{\mathrm{a}}$ & $0.64 \pm 0.01^{\mathrm{a}}$ \\
\hline 2. & Monovalent (HVT) & 10 & $316.46 \pm 5.54^{\mathrm{b}}$ & $0.67 \pm 0.03^{b}$ & $0.88 \pm 0.03^{\mathrm{b}}$ \\
\hline 3. & Unvaccinated control & 5 & $292.05 \pm 4.68^{\mathrm{a}}$ & $0.90 \pm 0.03^{\mathrm{c}}$ & $1.11 \pm 0.05^{\mathrm{c}}$ \\
\hline
\end{tabular}

10-day-old chickens were intravenously inoculated by 1,000 PFU of MDV isolate Ind/TN/12/03 /chick. ${ }^{\mathrm{A} B \mathrm{~B}, \mathrm{C}}$ Mean \pm standard error. In each column, different superscript letters are statistically significant at $P<0.01$. The values carrying different superscript letters $(\mathrm{a}, \mathrm{b})$ are significantly different, values carrying same superscript (a, a) are statistically not significant.

Table 4. Comparison of body weight and spleen weight in vaccinated (bivalent and monovalent) and unvaccinated birds challenged with isolate Ind/TN/12/03 in $12^{\text {th }}$ and $16^{\text {th }}$ week

\begin{tabular}{lccccccc}
\hline \multirow{2}{*}{ No. } & Vaccinated group & \multicolumn{2}{c}{ Number of birds sacrificed } & \multicolumn{2}{c}{ Body weight $(\mathbf{g}) \mathbf{A}$} & Spleen weight $(\mathbf{g})$ B \\
\cline { 3 - 7 } & & 12th week & 16th week & 12th week & 16th week & 12th week & 16th week \\
\hline 1. & Bivalent (SB1 + HVT) & 10 & 16 & $707.50 \pm 8.34^{\mathrm{c}}$ & $961.77 \pm 12.49^{\mathrm{c}}$ & $1.41 \pm 0.15^{\mathrm{a}}$ & $1.60 \pm 0.05^{\mathrm{a}}$ \\
2. & Monovalent (HVT) & 10 & 12 & $630.30 \pm 9.81^{\mathrm{b}}$ & $753.56 \pm 14.36^{\mathrm{b}}$ & $2.45 \pm 0.21^{\mathrm{b}}$ & $2.27 \pm 0.15^{\mathrm{b}}$ \\
3. & Unvaccinated control & 5 & 02 & $468.40 \pm 17.18^{\mathrm{a}}$ & $559.26 \pm 18.37^{\mathrm{a}}$ & $2.96 \pm 0.27^{\mathrm{b}}$ & $3.31 \pm 0.27^{\mathrm{c}}$ \\
\hline
\end{tabular}

10-day-old chickens were intravenously inoculated by 1,000 PFU of MDV isolate Ind/TN/12/03/chick.

${ }^{\mathrm{A}, \mathrm{B}}$ Mean \pm standard error. In each column, different superscript letters are statistically significant at $P<0.01$. The values carrying different superscript letters $(a, b)$ are significantly different, values carrying same superscript $(a, a)$ are statistically not significant.

Table 5. Comparison of mortality and lymphoma incidence in vaccinated (bivalent and monovalent) and unvaccinated birds challenged with isolate Ind/TN/12/03 till $16^{\text {th }}$ week

\begin{tabular}{lccccc}
\hline No. & Vaccinated group & No. of birds & Mortality (\%) & Lymphoma (\%) & MD (\%) \\
\hline 1. & Bivalent (SB1 + HVT) & 40 & 10 & 25 \\
2. & Monovalent (HVT) & 40 & 20 & 37.5 \\
3. & Unvaccinated Control & 20 & 40 & 60.0 & 100 \\
\hline
\end{tabular}



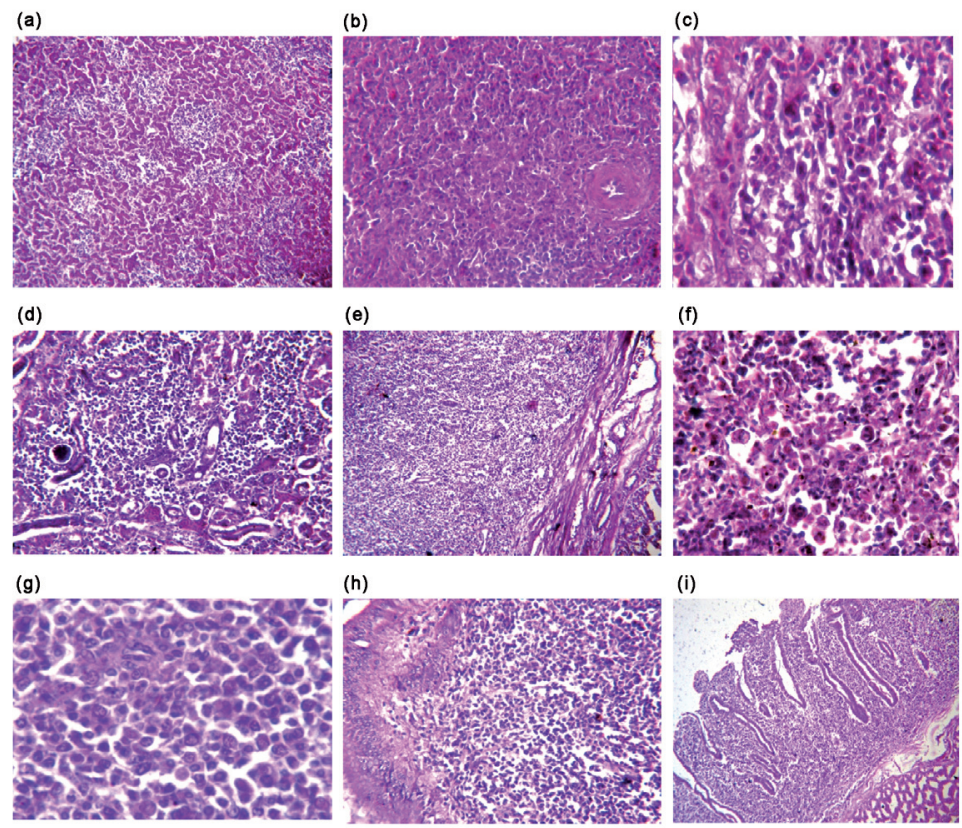

(h)

(i)
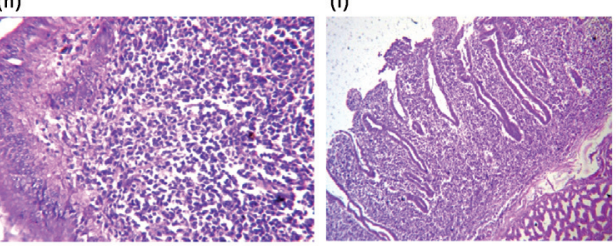

Fig. 5

Histopathology induced by MDV field isolate (Ind/TN/12/03) in unvaccinated birds (a-e) and vaccinated birds (f-i) (trial-I \&II) (a) Liver showing multiple islands of lymphocytic aggregation among hepatic parenchyma (H\&E, 100x); (b) spleen showing marked infiltration of pleomorphic neoplastic lymphocytes (H\&E, 400x); (c) heart showing distorted myocardium due to heavily infiltrating pleomorphic lymphoid cells (H\&E, 400x); (d) kidney revealing massive inter tubular infiltration of pleomorphic lymphoid cells and contracted glomeruli (H\&E, 100x); (e) proventriculus showing massive infiltration of mononuclear cells in the mucosa resulting in marked thickening of the organ (H\&E, 40x); (f) spleen showing characteristic nuclear changes of neoplastic lymphocytes (HVT)(H\&E, 400x); (g) spleen showing minimal infiltration of pleomorphic lymphoid cells (HVT+SB1)(H\&E, 400x); (h) proventriculus showing massive infiltration of pleomorphic cells (HVT) (H\&E, 100x); (i) proventriculus showing mild mucosal degeneration with heavy infiltration of lymphocytes causing thickening of the organ (HVT+SB1)(H\&E, 40x).

The isolation of highly oncogenic strains of MDV has been reported before (Witter et al., 1980; Raja et al., 2009). Most of these isolates were obtained from vaccination breaks in broiler breeders and growers. The highly oncogenic RB-IB virus (Schat et al., 1981) was isolated from a flock of laying birds. This virus was clearly able to cause significant mortality in HVT-vaccinated, genetically susceptible chickens, not unlike results reported by others (Witter et al., 1980; Witter, 1982). Even though RB-IB is very virulent strain it has not been observed to cause the so-called EMS (Witter et al., 1980). It is contradictory and interesting to note the occurrence of EMS in experimental birds caused by the field isolate of this study. Ind/TN/12/03 is considered to be a vv strain and its nucleotide sequences are also similar to RB1B.

Witter (1997) reported that the percentage of protection of HVT against vv MDV is usually lower than that of JM, a prototype virulent MDV strain and similarly, while the protective level of HVT plus SB1 against vv MDV is lower than against Md5, a prototype vv MDV strain. The percentage of protection of HVT or HVT plus SB1 was lower against challenge with Ind/TN/12/03. So, according to these results,
Ind/TN/12/03 may belong to vv MDV pathotypes. These findings are in agreement with Buscaglia et al. (2004).

Significant spleen enlargement was noticed in vaccinated group when compared to unvaccinated control. This indicates that the isolate evaded the vaccine immunity, has cytolytic activity in spleen and functions in transfer of virus particles from B cells to T cells. These findings correlate with that of Jeurissen et al. (1989).

The percentage of mortality in our study induced by Ind/ TN/12/03 was high in unvaccinated control (40\%) when compared to bivalent group (10\%) and monovalent group (20\%). Dudnikova et al. (2007) observed that very virulent plus strain 648A produced 11 and $23 \%$ of lymphoma in bivalent and monovalent vaccinated group respectively and $90 \%$ mortality in unvaccinated group. The results are in accordance with Dudnikova et al. (2007) however in unvaccinated control group the mortality is lower because only 20 birds were used in this group. Ten out of 20 birds were sacrificed till $12^{\text {th }}$ week excluding five birds which died between 8 and 18 days after challenge and most of the mortalities are recorded only after $12^{\text {th }}$ week in vaccinated and unvaccinated 
groups. Moreover, even if 648A is a very virulent plus strain and EMS were not observed in vaccinated groups.

This method of pathotyping is based on reduction in body and relative bursa Fabricii weight, percentage of lymphoma incidence, over all mortality patterns and magnitude of pathogenesis in vaccinated flocks induced by field isolates and prototype reference viruses by earlier workers. This method is useful to laboratories where prototype reference strains of MDV are not available and can be done by using local chicken strains.

Acknowledgement. We are indeed immensely pleased to thank Tamilnadu Veterinary and Animal Sciences University, Chennai, India for providing necessary facilities to carryout this research work.

\section{References}

Bancroft JD, Stevens A (1996): Theory and practice of histological techniques. 4th ed. Churchill Livingstone, London.

Barrow A, Venugopal K (1999): Molecular characteristics of very virulent European MDV isolates. Acta Virol. 43, 90-93.

Bublot M, Sharma J (2004): Vaccination against Marek's disease. In Davison F, Nair V (Ed.): Marek's Disease an Evolving Problem. Elsevier Academic Press, pp. 168-182. http:// dx.doi.org/10.1016/b978-012088379-0/50017-7

Bullow VV, Biggs PM (1975): Differentiation between strains of Marek's disease virus and turkey herpesvirus by immunofluorescence assays. Avian Pathol. 4, 133-146. http:// dx.doi.org/10.1080/03079457509353859

Buscaglia C, Nervi P, Miguel R (2004): Characterization of four very virulent argentinian strains of Marek's disease virus and the influence of one of those isolates on synergism between Marek's disease vaccine viruses. Avian Pathol. 33, 190-195. http://dx.doi.org/10.1080/03079450310001652103

Churchill AE, Chubb RC, Payne LN (1969): Immunization against Marek's disease using a live attenuated virus. Nature 221, 744-747. http://dx.doi.org/10.1038/221744a0

Dudnikova E, Norkina1 S, Vlasov A, Slobodchuk A, Lee L.F, Witter RL (2007): Evaluation of Marek's disease field isolates by the "best fit" pathotyping assay. Avian Pathol. 36, 135-143. http://dx.doi.org/10.1080/03079450701209857

Gopal S, Manoharan P, Kathaperumal K, Chidambaram B, Divya KC (2012): Differential detection of avian oncogenic viruses in poultry layer farms and turkeys by use of multiplex PCR. J. Clin. Microbiol. 50, 2668-673. http:// dx.doi.org/10.1128/JCM.00457-12

Handberg KJ, Nielsen OL, Jergensen PH (2001): The use of serotype 1 and serotype 3 - specific polymerase chain reaction for the detection of Marek's disease virus in chickens. Avian Pathol. 30, 243-249. http://dx.doi. org $/ 10.1080 / 03079450120054659$

Imai K, Yuasa N (1988): Pathogenicity of Marek's disease virus isolated in Japan in two genetically different strains of chickens, PDL-1 AND P-2 lines. In Kato S, Horiuchi T,
Mikami T, Hirai K (Eds): Advances in Marek's Disease Research. Osaka : Japanese Association on Marek's Disease, pp. 414-418.

Imai K, Yuasa N, Iwakiri, $\mathrm{H}$, Nakamura $\mathrm{K}$, Hihara $\mathrm{H}$, Ishita $\mathrm{T}$, Inamoto A, Okamoto I, Ohta K, Maeda M (1992): Characterization of very virulent Mareks disease viruses isolated in Japan. Avian Pathol. 21, 119-126. http://dx.doi. org/10.1080/03079459208418824

Jeurissen SH, Scholten R, Hilgers LA, Pol JM, De Boer GF (1989): In situ detection by monoclonal antibody D-35.1 of cells infected with Marek's disease virus that interact with splenic ellipsoid-associated reticulum cells. Avian Dis. 33, 657-663. http://dx.doi.org/10.2307/1591141

Jurajda V, Halouzka R (1988): Isolation of the pathogenic virus of Marek's disease from the flock of chickens vaccinated by the turkey herpes vaccine. Veterinarni Medicina 33, 741-746.

Kamaldeep PC, Sharma N, Jindal, Narang G (2007): Occurrence of Marek's disease in vaccinated poultry flocks of Haryana (India). Int. J. Poult. Sci. 6, 372-377. http://dx.doi. org/10.3923/ijps.2007.372.377

Liu X, Guan E, Wu C, Zhang R (1996): Characterization of very virulent strains of Marek's disease virus from vaccinated chickens in Eastern China. In Silva RF, Cheng HH, Coussens PM, Lee LF, Velicer LF (Eds): Current Research on Marek's Disease. Kennett Square, PA, American Association of Avian Pathologists, pp. 142-147.

Nair V (2005): Evolution of Marek's disease-a paradigm for incessant race between the pathogen and the host. Vet. J. 170, 175-183. http://dx.doi.org/10.1016/j.tvjl.2004.05.009

Okazaki W, Purchase HG, Burmester BR (1970): Protection against Marek's disease by vaccination with a Herpesvirus of turkeys. Avian Dis. 14, 413-429. http://dx.doi. org $/ 10.2307 / 1588488$

Powell PC, Lombardini F (1986): Isolation of very virulent pathotypes of Marek's disease virus from vaccinated chickens in Europe. Vet. Rec.118, 688-691. http://dx.doi.org/10.1136/ vr.118.25.688

Raja A, Dhinakar Raj G, Bhuvaneswari, P, Balachandran C, Kumanan K (2009): Detection of virulent Marek's disease virus in poultry in India. Acta Virol. 53, 255-260. http:// dx.doi.org/10.4149/av 2009 $04 \quad 255$

Schat KA, Baranowski E (2007): Animal vaccination and the evolution of viral pathogens. Review Scientific Technique Office International Epizootics 26, 327-338.

Schat KA, Calnek BW, Fabricant J, Abplanalp H (1981): Influence of oncogenicity of Marek's disease virus on evaluation of genetic resistance. Poult. Sci. 60, 2559-2566. http://dx.doi. org/10.3382/ps.0602559

Schat KA, Calnek BW, Fabricant J (1982): Characterization of two highly oncogenic strains of Marek's disease virus. Avian Pathol. 11, 593-605. http://dx.doi. org/10.1080/03079458208436134

Sung HW (2002): Recent increase of Marek's disease in Korea related to the virulence increase of the virus. Avian Dis. 46, 517-524. http://dx.doi.org/10.1637/0005-2086(2002)046[0517:RIOMSD]2.0.CO;2 
Supplemental assay method for titration of cell associated Marek's disease vaccines of serotypes 1, 2, OR 3 (2005): United States Department of Agriculture, Animal and Plant Health Inspection Service, pp. 1-15.

Suresh P, Johnson Rajeswar J, Sukumar K, Harikrishnan TJ, Srinivasan P (2013): Incidence of Marek's disease in vaccinated flocks. Int. J. Food, Agri. Vet. Sci. 3, 200-202.

Tian MX, Deng R, ZhaoY, Li M, Cao SJ, Wen XT, Huang Y (2012): Isolation of a field Marek's disease virus with acute oncogenicity from tibetan chickens in China and sequence analysis of oncogenic genes. Adv. Mat. Res. 343, 538-544.

Venugopal K, Bland AP, Ross LJN, Payne LN (1996): Pathogenicity of an unusual highly virulent Marek's disease virus isolated in the United Kingdom. In Silva RF, Cheng HH, Coussens PM, Lee LF, Velicer LF (Eds): Current research on Marek's disease. Kennett Square, PA, American Association of Avian Pathologists, pp. 119-124.

Witter RL (1982): Protections by attenuated and polyvalent vaccines against highly virulent strains of Marek's disease virus. Avian Pathol. 11, 49-62. http://dx.doi. org/10.1080/03079458208436081

Witter RL (1983): Characteristics of Marek's disease viruses isolated form vaccinated commercial chicken flocks: association of viral pathotype with lymphoma frequency. Avian Dis. 27, 113-132. http://dx.doi.org/10.2307/1590377
Witter RL (1988): Very virulent Marek's disease viruses: importance and control. In Proceedings of the 18th World's Poultry Congress. Japan, Nagoya.

Witter RL (1997): Increased virulence of Marek's disease virus field isolates. Avian Dis. 41, 149-163. http://dx.doi. org/10.2307/1592455

Witter RL (2001): "Marek's disease vaccines-past, present and future (Chicken vs virus - a battle of the centuries)." In Schat KA et al. (Ed.): Current Progress on Marek's Disease Research. American Association of Avian Pathologists, Kennett Square, Pa, USA, pp. 1-9.

Witter RL, Schat KA (2003): Marek's disease. In Calnek BW (Ed.): Diseases of poultry. 11th ed. Iowa State University Press, Ames, Iowa, pp. 407-465.

Witter RL, Sharma JM, Fadly AM (1980): Pathogenicity of variant Marek's disease virus isolates in vaccinated and unvaccinated chickens. Avian Dis. 24, 210-232. http://dx.doi. org/10.2307/1589781

Witter RL, Calnek BW, Buscaglia C, Gimeno IM, Schat KA (2005): Classification of Marek's disease viruses according to pathotype: philosophy and methodology. Avian Pathol. 34, 75-90. http://dx.doi. org/10.1080/03079450500059255 